\title{
Game Theory Approach to Solve Economic Dispatch Problem
}

\author{
Nezihe Yildiran and Emin Tacer
}

\begin{abstract}
This paper presents a game theory application for economic dispatch problem. In this application, economic dispatch problem has been applied to 6 thermal stations in 14-bus, $380 \mathrm{kV}$ power system in Turkey, by taking the generator limits and total demand into account, but transmission losses have been neglected. To find the optimum dispatch strategy Nash equilibrium has been used with MATLAB. Instead of following any particular strategy, the entire system has been analyzed. At the end of this paper, it was shown; calculated system total cost is smaller than the total cost of genetic algorithm and Lagrange function applications.
\end{abstract}

Index Terms-Economic dispatch, game theory, Nash equilibrium, optimization.

\section{NOMENCLATURE}

$C_{i}$ : Cost of i-th generator $[\$ / \mathrm{h}]$.

$\alpha_{i}$ : Cost coefficient of $\mathrm{i}$-th generator [\$/h] .

$\beta_{i}$ : Cost coefficient of $\mathrm{i}$-th generator [\$/MWh].

$\gamma_{i}$ : Cost coefficient of $\mathrm{i}$-th generator $\left[\$ / \mathrm{MW}^{2} \mathrm{~h}\right]$.

$P_{i}$ : Generated real power of i-th generator [MW].

$n$ : Number of generating units.

$C_{T}$ : Total cost of generators $[\$ / \mathrm{h}]$.

$P_{D}$ : Total load demand [MW].

$P_{L}$ : Transmission losses [MW].

$P_{i(\min )}$ : Minimum generating limits for plant $i[\mathrm{MW}]$.

$P_{i(\max )}$ : Maximum generating limits for plant $i[\mathrm{MW}]$

GP_ $i$ : $i$-th generation plant.

\section{INTRODUCTION}

Economic dispatch is generally defined as the determining the operation points of the generation plants at the lowest cost to supply demand while considering generator limits and transmission line lengths.

Nowadays, energy demand is increasing because of growing population and increasing of the living standard level in the world. On the other hand, non-renewable energy sources are decreasing and renewable energy sources are getting popular with their discrete production areas. Furthermore, transmission line length, which is the distance between power generation plants and load centers, is changing. Otherwise, in an interconnected system, the power plants use different sources such as natural gas, water, and coal; and the prices of these sources are variable. Under normal operating conditions, the total generation capacity of

Manuscript received July 21, 2014; revised May 9, 2015.

Nezihe Yildiran is with Bahcesehir University, Energy Systems Engineering Department, Istanbul, Turkey (e-mail: nezihe.kucukyildiran@eng.bahcesehir.edu.tr).

Emin Tacer was with Bahcesehir University, Energy Systems Engineering Department, Istanbul, Turkey. the generation plants is more than the total load demand and losses. Thus, there are many options for scheduling power generation. Hence, today's economic dispatch problem is rapidly gaining importance, because energy is very precious now.

In summary, for any specified load condition economic dispatch determines the power output of each power plant which will minimize the overall cost of fuel needed to maintain the system total demand. Economic dispatch focuses upon coordinating the production costs at all power plants operating on the power system. So, energy should be used efficiently and rightly. Analyzing ED problem helps finding best scheduling solutions. The optimization of economic dispatch shows the economic value of the network operator. The economic dispatch is a relevant procedure in the operation of a power system. Because of the daily demand variation on the power system, the utility has to decide on the basis of economics which generators to start up, which to shut down, and in what order.

Over the past years, economic dispatch (ED) problem is studied and solved by using different mathematical or optimization methods in the literature. One of the literature applications is Hopfield neural network method, which is used by Yalcinoz and Short to solve the ED problem [1]. In the Yalcinoz's paper, smaller solution time and smaller operation costs according to classical optimization methods were founded. Generally, genetic algorithm has applied to solve the ED problem. Kurban and Basaran solved the ED problem with using Lagrange functions [2]. Dosoglu, Duman, and Ozturk used Kurban and Basaran's [2] system and applied genetic algorithm [3] to the same system. Afterward, Gaing have proposed particle swarm optimization method to solve the ED problem [4]. Gaing showed the result of proposed method is superior to genetic algorithm results. Park, Kim, and Jung used game theory to solve the ED problem [5]. The proposed model in [5] uses a strategy and decides the optimum economic dispatch strategy according to bidding prices.

In this paper, game theory with Nash equilibrium is applied by using Kurban and Basaran's [2] 14 bus power system to analyze the economic dispatch of real power generation. With this application, entire system is handled instead of Park, Kim, and Jung's application [5]. Nash equilibrium points are founded to decide the optimal operating points of generators.

The rest of the paper is organized as follows: Section II explains the economic dispatch problem. Section III defines the concept of game theory. Section IV presents a solution for a general economic dispatch problem using game theory. Section V shows MATLAB simulation results of the real example system. Conclusions are given in Section VI. 


\section{ECONOMIC DisPATCH PROBLEM}

Economic operation is very essential for a power system to return a profit on the capital investment. To determine the economic distribution of load between the various generating units, the variable operation costs of the plant must be expressed in terms of the power output. Fuel cost is the principal factor in fossil power plants. Analysis is based on the economics of fuel cost with the realization that other costs which are a function of power output can be included in the expression for fuel cost.

The factors influencing power generation at minimum cost are operating efficiencies of power generators, fuel cost, and transmission losses. As an example, the most efficient generator in the power system does not guarantee minimum total cost, because of it may be located in an area where fuel cost is high. Hence, the economic dispatch problem is to determine the generation of different plants while the total operating cost is minimum. The operating cost plays a key role in the economic scheduling.

The objective function of the economic dispatch problem is known as cost function. Cost functions consist of fuel cost, no load operating costs and initial operation costs of the generation plants. The aim of economic dispatch problem is minimizing the total cost of generation plants. Also, ED satisfies constraints such as total demand, generation limits, and transmission losses [6].

Generally, the input to the thermal power plants is measured in Btu/h (British thermal units per hour) and the output is measured in MW. An input-output curve of a thermal plant known as a heat-rate curve (Btu/h versus output power of the plant). Converting the ordinate of heat-rate curve from Btu/h to $\$ / \mathrm{h}$ presents the fuel-cost curve. Cost function of the generation plants gives the function of that fuel-cost curve. In all practical models, the cost function of i-th generation plant can be represented as a quadratic function of generated power and the formula is given by [6], [7].

$$
C_{i}=\alpha_{i}+\beta_{i} P_{i}+\gamma_{i} P_{i}^{2}
$$

System total cost function for $\mathrm{n}$ generator is defined as from (1),

$$
C_{T}=\sum_{i=1}^{n} C_{i}=\sum_{i=1}^{n} \alpha_{i}+\beta_{i} P_{i}+\gamma_{i} P_{i}^{2}
$$

The problem is to find the real power generation for each plant to make the total cost function minimum and supply the total load demand. Equality constraint of the system is given by

$$
\sum_{i=1}^{n} P_{i}=P_{D}+P_{L}
$$

The simplest economic dispatch problem is the scenario when transmission line losses are neglected. This problem does not consider system configuration and transmission line impedances. In theory, the model assumes that the system has only one bus with all generation plants and all loads connected to that bus.

When transmission distances are very small and load density is very high, transmission losses may be neglected and the economic dispatch of the generation plants is achieved with all plants operating at equal production cost. So, to simplify the system computations, transmission losses may be neglected. In this case, the system can be shown as in Fig. 1 and equality constraint will be

$$
\sum_{i=1}^{n} P_{i}=P_{D}
$$

For most economic operation, when losses are neglected with no generator limits, all plants must operate at equal production cost while satisfying the equality constraint.

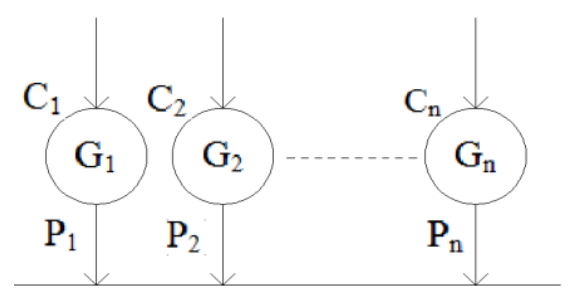

Fig. 1. System with n generators.

The power output of any generator should not exceed its operating ratings which are defines as the maximum and minimum generation amounts of the generator. So, the generator limits constraint (inequality constraint) is expressed as

$$
P_{i(\min )} \leq P_{i} \leq P_{i(\max )} \quad i=1,2, \ldots, n
$$

The problem is to find the real power generation for each plant such that the objective function as defined by (2) is minimum, subject to the equality constraint given by (4) and the inequality constraint given by (5).

\section{GAME THEORY}

Game theory is a discipline which helps to find out optimum choice. It is used firstly in economics to analyze different strategies. Today, game theory is applied to other branches of science. The fundamental insight of game theory was to apply the logic of games to events in real life.

A game-theoretic model is an environment where actions of each decision maker interact with other decision makers. Game theory uses economic and mathematical tools to solve decision making problems.

A game is a description of strategic interaction that includes the constraints on the actions that the players can take and the players' interests, but does not specify the actions that the players take. A solution is a systematic description of the outcomes that may emerge in a family of games. Game theory suggests reasonable solutions for classes of games and examine their properties.

Nash equilibrium is one of the most basic concepts in the game theory and the widespread method of predicting the outcome of a strategic decisions. First of all, Antoine Cournot used game theory and Nash equilibrium in 1838. The study was about duopoly. In Cournot's theory, firms decide their production amounts to maximize their own profit and it depends on the outputs of the others. During the 1950s, John Nash proved that finite games have always an equilibrium point. Equilibrium is defined as a stable outcome based on the 
payoffs received by players at the end of the game. Also, all players choose strategies which are best for them according to given their opponents' choices at this equilibrium point [8]. In Nash equilibrium, each player responds to the others with best decision.

A game includes three key ingredients: players, actions, and payoffs. The description of these three elements and their functions will be explained in the following example:

- A set of players $N=(\{1,2, \ldots, n\})$ is a finite set of $n$, indexed by $i$.

- A set of actions (pure strategies) available to each player $\left(a=\left(a_{1}, a_{2}, \ldots, a_{n}\right) \in A\right)$ determines their possible moves or strategies.

- A payoff functions $\left(u=\left(u_{1}, u_{2}, \ldots u_{n}\right)\right)$ represent each player's preferences and shows what players receive at the end of the game.

Best response in a game is defined as $a_{i}^{*} \in B R\left(a_{-i}\right)$ if $\forall a_{i} \in A_{i}, u_{i}\left(a_{i}^{*}, a_{-i}\right) \geq, u_{i}\left(a_{i}, a_{-i}\right)$.

$a=\left(a_{1}, a_{2}, \ldots, a_{n}\right)$ is a pure strategy Nash equilibrium if $\forall i, a_{i} \in B R\left(a_{-i}\right)$.

On the other hand, the existence of an equilibrium is an important situation in game theory. The equilibrium point can be pure strategy or mixed strategy. When the pure strategy equilibrium point exists, equilibrium point shows maximum profit. If there is mixed strategy equilibrium point, the players or companies can choose maximum profit with a probability. Briefly, a pure strategy Nash equilibrium is a point which any player cannot gain a higher payoff deviating its profile alone [9].

Table I shows an example payoff matrix of the two player game. In this table, player 1 (P1) and player 2 (P2) have two strategies (strategy "A" and strategy "B"). The payoffs of these strategies are also given in the same table. If player 1 choose strategy "A", then player 2 will choose strategy "B" due to the higher payoff $(1,2)$. After that, player " $A$ " changes his strategy to " $\mathrm{B}$ ", but player 2 does not want to change his strategy in this case, must stay at strategy "B" $(3,3)$. As a result of this game, $(\mathrm{B}, \mathrm{B})$ strategy profile is the unique and pure Nash equilibrium point.

TABLE I: AN EXAMPLE OF TwO PLAYER GAME
\begin{tabular}{|c|c|c|}
\hline $\mathbf{P 1} \backslash \mathbf{P} 2$ & $\mathbf{A}$ & $\mathbf{B}$ \\
\hline $\mathbf{A}$ & $(0,0)$ & $(1,2)$ \\
\hline $\mathbf{B}$ & $(2,1)$ & $(3,3)$ \\
\hline
\end{tabular}

\section{ECONOMIC DisPATCH PROBLEM USING GAME THEORY}

Before the system analyze, game theory elements of the system should be clarified. In this paper, game theory elements with their power generation system equivalents are defined at Table II and flow chart of the proposed algorithm is given at Fig. 2.

TABLE II: GAME THEORY AND POWER SYSTEM EQUIVALENT

\begin{tabular}{|c|c|}
\hline Game Theory Elements & Power System Equivalent \\
\hline Players & Generation Plants \\
\hline Strategies & Produced Power \\
\hline Payoffs & $1 / 0$ According to Demand \\
\hline
\end{tabular}

To explain the algorithm, an example two generator simplified game can be defined and generator payoff matrix is given in Table III. According to the Table III, two players, generation plant 1 and generation plant 2 has been defined with two different production amounts; $100 \mathrm{MW}$ or $200 \mathrm{MW}$ options.

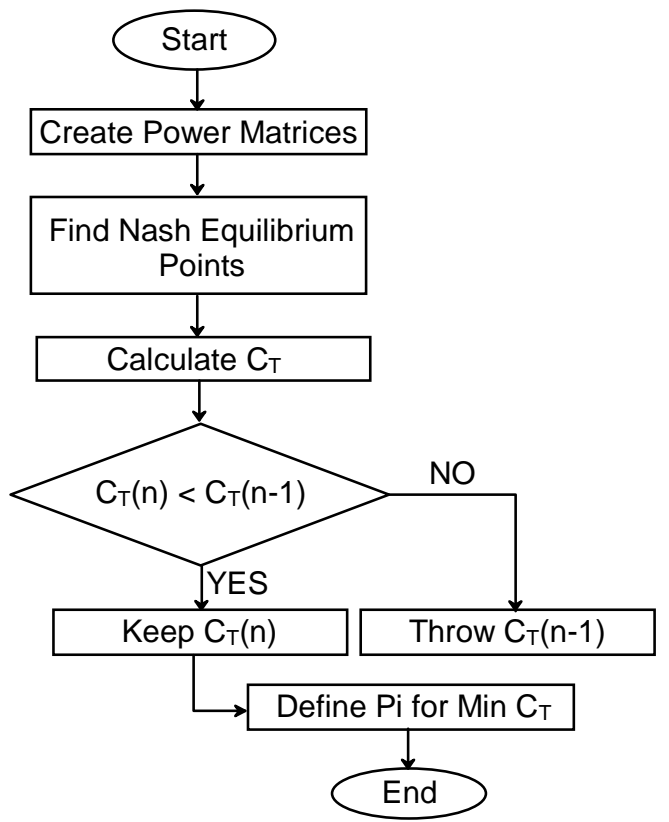

Fig. 2. Flow chart of proposed algorithm.

TABLE III: NASH EQUILIBRIUM POINTS OF TWO GENERATION PLANT

\begin{tabular}{|c|c|c|}
\hline GP_1 $\backslash$ GP_2 & 100 MW & 200 MW \\
\hline 100 MW & $(0,0)$ & $(1,1)$ \\
\hline 200 MW & $(1,1)$ & $(0,0)$ \\
\hline
\end{tabular}

If the system total demand is equal to $300 \mathrm{MW}$, Nash equilibrium points, which supply the total demand are 100 MW, $200 \mathrm{MW}$ and $200 \mathrm{MW}, 100 \mathrm{MW}$. Nash equilibrium points are signed in Table IV.

TABLE IV: AN EXAMPLE OF TWO GENERATION PLANT
\begin{tabular}{|c|c|c|}
\hline GP_1 $\backslash$ GP_2 & $\mathbf{1 0 0} \mathbf{M W}$ & $\mathbf{2 0 0 M W}$ \\
\hline $\mathbf{1 0 0} \mathbf{M W}$ & $(0,0)$ & $(1,1)$ \\
\hline $\mathbf{2 0 0} \mathbf{M W}$ & $(1,1)$ & $(0,0)$ \\
\hline
\end{tabular}

After the loop of the presented algorithm, detected Nash equilibrium points are used to calculate total cost of the system. Minimum of calculated costs gives the system minimum total cost, in other words this point shows optimum operating strategy.

\section{Simulation Results}

Fig. 3 shows 14 buses, 6 thermal generators power system in Turkey. The main objective of this paper is to solve this system using game theory Nash equilibrium. Also, Table V gives the generator coefficients and generator maximum and minimum values of 6 thermal power plants [2].

In this presented system, 6 thermal plants shows the players, the production amount of each generation plant shows the strategies, and the payoffs are determined according to the data at each point.

At the start of the game, all power possibilities of the 
generators were determined according to Table $\mathrm{V}$ system generator parameters. While the determination of the power possibilities, generator minimum and maximum power production amounts are taken into account and step size (power increase interval amount) are decided. As an example, for Bursa Natural Gas station the possible power production changes between $318 \mathrm{MW}$ and $1432 \mathrm{MW}$, and step size is chosen as $0.0001 \mathrm{MW}$. After that, power values of each power plant which satisfy the total demand amount, are found out. These points show also the Nash equilibrium points of the system. Total cost of the system is calculated for each Nash equilibrium point. Finally, minimum of the calculated total costs gives the system optimum operating point. The generator power amounts at founded point give the operation values of the generators and shows the optimum operation strategy.

TABLE V: GENERATOR PARAMETERS

\begin{tabular}{|l|l|l|l|l|c|}
\hline Thermal Plants & $P_{i(\min )}$ & $P_{i(\max )}$ & $\alpha_{i}$ & $\beta_{i}$ & $\gamma_{i}$ \\
\hline $\begin{array}{l}\text { Bursa N. Gas } \\
(\mathrm{G} 1)\end{array}$ & 318 & 1432 & 6780.5 & 5.682 & 0.0106 \\
\hline Seyitömer (G2) & 150 & 600 & 1564.4 & 3.1288 & 0.0139 \\
\hline SomaB (G3) & 210 & 990 & 5134.1 & 6.2232 & 0.0168 \\
\hline Yeniköy (G4) & 110 & 420 & 1159.5 & 3.3128 & 0.0210 \\
\hline Kemerköy (G5) & 140 & 630 & 1697 & 3.2324 & 0.0137 \\
\hline Yatağan (G6) & 140 & 630 & 1822.8 & 3.472 & 0.0147 \\
\hline
\end{tabular}

At Table VI, the calculated total cost of the system with each generator production amount is given and compared with Lagrange Function (LF) [2] and genetic algorithm (GA) [3] solutions of the same system in the literature.

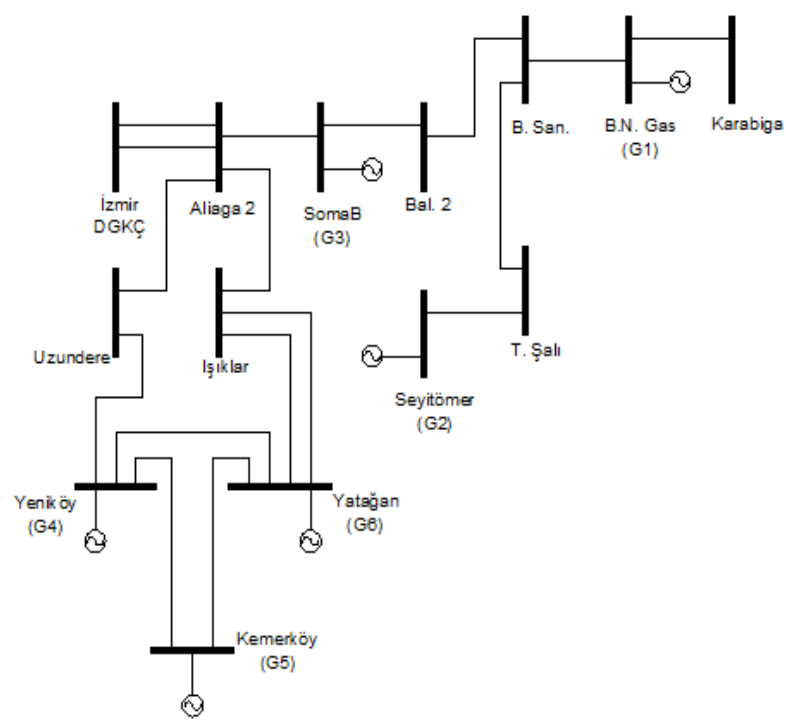

Fig. 3.14 bus, 6 generator system [2].

Total demand is obtained by the generation plants with a calculation error. Error amount shows the difference between calculated demand amount and target demand amount. In game theory results, obtained total generator production amounts is $2735 \mathrm{MW}$ while demand is $2734.9 \mathrm{MW}$. There is 0.1 MW calculation error. Comparison with other literature solutions shows that game theory error amount is approximately less than approximately $95 \%$ of others error amount.

Table VI shows clearly the minimum total cost is achieved by game theory solution with minimum error.

TABLE VI: COMPARISON OF THE RESULTS WITH ERROR (DEMAND=2734.9 MW)

\begin{tabular}{|c|c|c|c|c|c|c|c|c|}
\hline Method & $\begin{array}{l}\text { Error } \\
{[\mathrm{MW}]}\end{array}$ & $\begin{array}{c}\text { Bursa N. Gas } \\
\text { (G1) }[\mathrm{MW}]\end{array}$ & $\begin{array}{l}\text { Seyitömer } \\
\text { (G2) [MW] }\end{array}$ & $\begin{array}{c}\text { SomaB } \\
\text { (G3) }[\mathrm{MW}]\end{array}$ & $\begin{array}{c}\text { Yeniköy } \\
\text { (G4) [MW] }\end{array}$ & $\begin{array}{l}\text { Kemerköy } \\
\text { (G5) [MW] }\end{array}$ & $\begin{array}{c}\text { Yatağan } \\
\text { (G6) }[\mathrm{MW}]\end{array}$ & $\begin{array}{c}\text { Total Cost } \\
{[\$ / \mathrm{h}]}\end{array}$ \\
\hline Lagrange Function [2] & 42.7319 & 573.0010 & 520.3039 & 352.5975 & 335.5975 & 523.9189 & 472.2131 & $48.481,0000$ \\
\hline Genetic Algorithm [3] & 44.0000 & 552.0396 & 543.4736 & 322.6902 & 353.4248 & 515.1527 & 492.1534 & $48.454,9881$ \\
\hline Game Theory & 0.1000 & 555.0000 & 515.0000 & 334.0000 & 337.0000 & 519.0000 & 475.0000 & $47.662,6355$ \\
\hline
\end{tabular}

TABLE VII: COMPARISON OF THE RESULTS WITHOUT ERROR

\begin{tabular}{|c|c|c|c|c|c|c|c|c|}
\hline Method & $\begin{array}{l}\text { Demand } \\
{[\mathrm{MW}]}\end{array}$ & $\begin{array}{c}\text { Bursa N. Gas } \\
\text { (G1) }[\mathrm{MW}]\end{array}$ & $\begin{array}{l}\text { Seyitömer } \\
\text { (G2) [MW] }\end{array}$ & $\begin{array}{c}\text { SomaB } \\
\text { (G3) [MW] }\end{array}$ & $\begin{array}{c}\text { Yeniköy } \\
\text { (G4) [MW] }\end{array}$ & $\begin{array}{l}\text { Kemerköy } \\
\text { (G5) [MW] }\end{array}$ & $\begin{array}{c}\text { Yatağan } \\
\text { (G6) [MW] }\end{array}$ & $\begin{array}{c}\text { Total Cost } \\
{[\$ / \mathrm{h}]} \\
\end{array}$ \\
\hline Genetic Algorithm [3] & 2734.9 & 554.0455 & 496.9588 & 320.8097 & 357.1712 & 519.2502 & 486.6204 & $47.679,2861$ \\
\hline Game Theory & 2734.9 & 554.9000 & 515.0000 & 334.0000 & 337.0000 & 519.0000 & 475.0000 & $40.313,9354$ \\
\hline
\end{tabular}

To get the exactly demand without error, error amount can be subtracted from a generation plant which has maximum cost coefficients to achieve lesser total cost. In this case, Generator 1 (Bursa N. Gas) has the maximum cost coefficients. So that, error amount was subtracted from Generator 1 to get the exact demand.

Table VII shows the generators operation amounts and minimum total cost without any error from demand. Moreover, total cost obtained from the game theory is $15.45 \%$ economy saving than total cost obtained from genetic algorithm.

\section{CONCLUSION}

In this paper, solving economic dispatch problem using game theory Nash equilibrium has been presented. In the case study, the proposed method has been applied to 14 bus, 6 thermal generators of power system, which is selected from the Turkish utility power system.

The presented algorithm results show that the proposed game theory method gives the minimum total cost of the system with minimum error instead of Lagrange functions results and genetic algorithm results. Furthermore, if the computation is revised to find minimum total cost without error, total cost decrease. Finally, the results of this study shows that game theory helps to find better results for solving economic dispatch problem and to get economy saving up to 15.45 percent.

This power system may be studied with transmission losses or another power system with different types of generators including renewable energy resources may be analyzed for future work.

\section{REFERENCES}

[1] T. Yalcinoz and M. J. Short, "Neural networks approach for solving economic dispatch problem with transmission capacity constraints," IEEE Trans. on Power Systems, vol. 13, no. 2, pp. 307-313, 1998.

[2] M. Kurban and U. Basaran, "Türkiye'deki 380kV'luk 14 baralı güç sisteminde ekonomik yüklenme analizi," presented at Electric-Electronic-Computer Engineering 11. National Convention and Exhibition, Istanbul, Turkey, Sept. 22-25, 2005. 
[3] M. K. Dosoglu, S. Duman, and A. Ozturk, "Genetik algoritma kullanarak ekonomik dağttım analizi: Türkiye uygulaması," Journal of Polytechnic, vol. 12, no. 3, pp. 167-172, 2009.

[4] Z. Gaing, "Particle swarm optimization to solving the economic dispatch considering the generator constraints," IEEE Trans. on Power Systems, vol. 18, no. 3, pp. 1187-1195, 2003.

[5] JB. Park, B. H. Kim, J. Kim, M. Jung, and J. K. Park, "A continuous strategy game for power transactions analysis in competitive electricity markets," IEEE Trans. on Power System, vol. 16, no. 4, pp. 847-855, 2001.

[6] H. Saadat, "Optimal dispatch of generation," Power System Analysis, ch. 7, pp. 257-277, Singapore: McGraw-Hill, 2004.

[7] N. V. Ramana, "Economic operation of power system," Power System Operation and Control, ch. 1, pp. 1-24, Pearson Education India, 2010.

[8] T. L. Turocy and B. V. Stengel. (October 2013). Game theory. London School of Economics. London, UK. [Online]. Available: http://www.cdam.lse.ac.uk/Reports/Files/cdam-2001-09.pdf

[9] G. A. Nasser, "Nash equilibrium," International Encyclopedia of the Social Sciences, pp. 540-542.

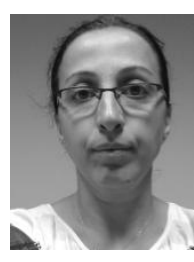

Nezihe Yildiran was born in Istanbul, Turkey, in 1980 She received the B.Sc. and M.Sc. degrees in electrical engineering in 2004 and 2007, respectively, from the Istanbul Technical University (ITU), Istanbul, Turkey. She is currently working toward the Ph.D. degree at Bahcesehir University, Istanbul, Turkey.

She has experience about power electronics research and development from the different companies between
2004 and 2012. She is a research assistant in the Energy Systems Engineering Department at Bahcesehir University since 2012. Her curren research interests include modeling and control of power electronic converters, modeling renewable energy sources, and power electronic applications of smart grid.

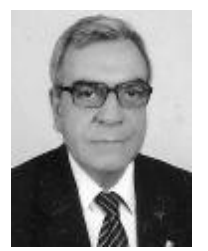

Emin Tacer received Ph.D. degree from the Electrical Engineering Faculty of İstanbul Technical University (ITÜEE) in 1977. He did works as a postdoctoral research fellow at University of Toronto, Canada in 1978. In 1979, he was a visiting professor at University of Michigan. He became an associate professor in 1982, and a full professor in 1988, İTÜEE.

He has been emeritus since July 17, 2006 and had been a faculty member from 2006 to 2014 in the Engineering Faculty a Bahcesehir University and since 2015 has been a faculty member of the Engineering Faculty at Aydın University. He has supervised $5 \mathrm{Ph} . \mathrm{D}$ dissertations and above $30 \mathrm{MSc}$. theses and he has been the advisor of 1 $\mathrm{Ph} . D$. theses currently. He has published 5 transaction paper, 14 international articles, 3 books, 28 research reports and course notes. He gave consultancy for different company. He worked on different administrative positions at ITÜ and the other university. His academic fields and research areas are renewable energy sources, photovoltaic power generation, wind power generation, electrical machines, power electronics and electromagnetic. 